\title{
Oxygenation Indices in Noninvasive Ventilation: Could They Predict Mortality in COVID-19?
}

\author{
Carol D'Silva@
}

Indian Journal of Critical Care Medicine (2021): 10.5005/jp-journals-10071-23956

"The best way to predict the future is to study the past, or prognosticate" -Robert Kiyosaki

Coronavirus disease-2019 (COVID-19) has plagued our lives and healthcare system since March, 2020. As of this day, the disease has already claimed close to $39,80,000$ lives around the world and $4,00,000$ lives in India alone since 2020 . $^{1}$ Hypoxemia in COVID-19 is attributed primarily to ventilation perfusion mismatch and intrapulmonary shunting, thereby causing an elevated alveolararterial gradient (A-a gradient). ${ }^{2}$ Another unique feature of COVID-19 is that the hypoxemia maybe disproportionate to the abnormalities in the lung compliance.

As clinicians, the simplest way to identify patient's oxygenation status is by measuring the oxygen saturation $\left(\mathrm{SpO}_{2}\right)$ with pulse oximetry. However, this must be correlated with the $\mathrm{FiO}_{2}$ at which the readings are taken. The estimation of $\mathrm{FiO}_{2}$ especially when the patient is not intubated or breathing at room air is exceedingly difficult. It has been seen that subjects on nasal prongs with $2 \mathrm{~L}$ of oxygen could have a $\mathrm{FiO}_{2}$ ranging from 24 to $35 \% .^{3}$ Arterial blood gases give us a better picture of patients oxygenation and ventilation status with parameters of $\mathrm{PaO}_{2}, \mathrm{PaCO}_{2}$, and $\mathrm{HCO}_{3}$. Low $\mathrm{PaO}_{2}$ remains to be the key parameter to measure a patient's oxygenation. Oxygen tension-based indices are usually used at the bedside by clinicians to assess the patient's response to the treatment and to quantify the severity of lung involvement. The popular indices used include the $\mathrm{A}$-a gradient, $\mathrm{PaO}_{2} / \mathrm{FiO}_{2}$ ratio or the Horowitz index, a/A ratio, and oxygenation index.

The A-a gradient, first described by Mellemgard, is based on the alveolar gas equation and gives a good insight into the differential diagnosis of hypoxemia. An increased A-a gradient often points to various pathologies involving the lung and right-to-left shunts. One of its main criticisms is that it is highly influenced by the $\mathrm{FiO}_{2}$ and shunt. The a/A ratio is on the other hand has been shown to give a better idea of the cause of oxygenation failure, with less influence by the fraction of inspired oxygen. Although this has been critiqued and shown to be true only in the case of large shunts. ${ }^{4}$

The $\mathrm{PaO}_{2} / \mathrm{FiO}_{2}$ ratio is simply the ratio of the alveolar oxygen tension by the fraction of inspired oxygen. $\mathrm{PaO}_{2} / \mathrm{FiO}_{2}$ ratio is common parlance during intensive care unit (ICU) rounds or handovers, much so during the recent pandemic. The $\mathrm{PaO}_{2} / \mathrm{FiO}_{2}$ ratio is an integral part of the acute respiratory distress syndrome (ARDS) definitions, both the American-European consensus conference (AECC) and Berlin's definition. Based on the $\mathrm{PaO}_{2} / \mathrm{FiO}_{2}$ ratios, the Berlin's criteria classifies ARDS into mild, moderate, and severe disease with an estimated mortality of 27,32 , and $45 \%$, respectively. ${ }^{5}$ This ratio has its share of limitations in that it gives no clue to the cause of hypoxemia or does not take the barometric pressure into consideration. Recently, Tobin et al. referred to the
Department of Critical Care Medicine, St. John's National Academy of Health Sciences, Bengaluru, Karnataka, India

Corresponding Author: Carol D'Silva, Department of Critical Care Medicine, St. John's National Academy of Health Sciences, Bengaluru, Karnataka, India, Phone: +91 9766397569, e-mail: calps80@gmail.com How to cite this article: D'Silva C. Oxygenation Indices in Noninvasive Ventilation: Could They Predict Mortality in COVID-19? Indian J Crit Care Med 2021;25(8):841-842.

Source of support: Nil

Conflict of interest: None

$\mathrm{PaO}_{2} / \mathrm{FiO}_{2}$ ratio as "the mismeasurement of all things oxygen" with regards to COVID-19. ${ }^{6}$ While $\mathrm{PaO}_{2} / \mathrm{FiO}_{2}$ ratio may have its share of fallacies, they carry the advantage of easy calculation at the bedside and widespread use. The respiratory index is not as frequently used as the other indices and has a similar clinical significance as that of the a/A ratio. The A-a gradient and $\mathrm{PaO}_{2} / \mathrm{FiO}_{2}$ ratio are also important variables in commonly used ICU scoring systems, like APACHE II and Sequential Organ Failure Assessment (SOFA). The use of A-a gradient has been shown to predict mortality in other clinical settings as well. In pediatric patients undergoing bone marrow transplantation, oxygenation index and $\mathrm{A}-\mathrm{a}$ gradient were shown to be good predictors of mortality. ${ }^{7}$ The A-a gradient has also shown to be a predictor in HIV patients who developed Pneumocystis pneumonia as well as an indication to initiate steroid therapy in these patients. ${ }^{8} \mathrm{~A}$ pilot study by Gabrielli et al showed that an elevated A-a gradient did have a significant correlation with ICU admission in COVID-19, but not with mortality. ${ }^{9}$

Invasive ventilation remains to be the cornerstone for the management of patients with severe ARDS. With COVID-19, clinicians over the world have opted for noninvasive strategies, like noninvasive ventilation (NIV), continuous positive airway pressure, or high-flow nasal oxygen therapy, at initial presentation as compared to invasive ventilation at the get-go. These noninvasive strategies have also been advocated in the surviving sepsis guidelines for COVID-19. ${ }^{10}$ The role and timing of intubation in COVID-19 patients are still highly debated. A recently published editorial even went on to state that "liberal use of invasive ventilation has been described as the surest way of increasing mortality,"11 One cannot also overlook the shortage of ventilators that occurred during the pandemic. Particularly in the devastating second wave of the COVID-19 pandemic, there was a heightened use of noninvasive ventilatory strategies owing to the shortage of ICU beds with ventilators across the country. Various 
investigators and clinicians have tried to study the predictors of mortality in COVID-19. These included age $>50$ years, male sex, presence of comorbidities, and higher inflammatory markers, like D-dimer, interleukin-6, C-reactive protein, cardiac troponins, and $\mathrm{SpO}_{2} / \mathrm{FiO}_{2}<400 .^{12,13}$ However, it is equally important to identify similar predictors in patients initiated on NIV.

In this month's issue, Gupta et al. have evaluated the utility of these oxygen tension indices to predict mortality in patients with COVID-19 receiving NIV, particularly the A-a gradient. ${ }^{14}$ The differences in these indices, which included the $\mathrm{PaO}_{2} / \mathrm{FiO}_{2}$ ratio, $\mathrm{A}-\mathrm{a}$ gradient, respiratory index, and a/A ratio, were significant among the COVID-19 survivors vs the nonsurvivors in this study. Optimal criteria for $\mathrm{ABG}$ parameters, like $\mathrm{PaO}_{2}, \mathrm{PaCO}_{2}$, and bicarbonate levels to predict mortality were also identified, although with varying degrees of sensitivity and specificity.

Simplifying predictors of mortality due to COVID-19 remains to be a challenge. While these oxygenation tension indices are fraught with fallacies, one cannot deny their simplicity to use and easy to calculate at the bedside. The use of these indices in combination with other measurable respiratory parameters and clinicopathological criteria would be needed to build a more robust model for prognostication for COVID-19.

\section{OrCID}

Carol D'Silva @ https://orcid.org/0000-0002-3920-1366

\section{References}

1. Ritchie H, Ortiz-Ospina E, Beltekian D, Mathieu E, Hasell J, Macdonald B, et al. Coronavirus pandemic (COVID-19). 2020. Retrieved from: https://ourworldindata.org/coronavirus.

2. Dhont S, Derom E, Van Braeckel E, Depuydt P, Lambrecht BN. The pathophysiology of 'happy' hypoxemia in COVID-19. Respir Res 2020;21(1):198. DOI: 10.1186/s12931-020-01462-5.

3. Bazuaye EA, Stone TN, Corris PA, Gibson GJ. Variability of inspired oxygen concentration with nasal cannulas. Thorax 1992;47(8):609- 611. DOI: 10.1136/thx.47.8.609.
4. Doyle JD. Arterial/alveolar oxygen tension ratio: a critical appraisal. Can Anaesth Soc J 1986;33(4):471-474. DOI: 10.1007/BF03010973.

5. ARDS Definition Task Force, Ranieri VM, Rubenfeld GD, Thompson BT, Ferguson ND, Caldwell E, et al. Acute respiratory distress syndrome: the Berlin definition. JAMA 2012;307(23):2526-2533. DOI: 10.1001/ jama.2012.5669.

6. Tobin MJ, Jubran A, Laghi F. $\mathrm{PaO}_{2} / \mathrm{FiO}_{2}$ ratio: the mismeasure of oxygenation in COVID-19. Eur Respir J 2021;57(3):2100274. DOI: 10.1183/13993003.00274-2021.

7. Litalien C, Derish M, DiCarlo J. Oxygenation index and alveolararterial oxygen gradient predict mortality in pediatric bone marrow transplantation 1998. Pediatr Res 1998;43:39. DOI: 10.1203/00006450199804001-00232.

8. Fei MW, Kim EJ, Sant CA, Jarlsberg LG, Davis JL, Swartzman A, et al. Predicting mortality from HIV-associated Pneumocystis pneumonia at illness presentation: an observational cohort study. Thorax 2009;64(12):1070-1076. DOI: 10.1136/thx.2009.117846.

9. Gabrielli M, Esperide A, Valletta F, Giancristofaro F, Santoro M, Santarelli $\mathrm{L}$, Franceschi F. Relationship between arterial-alveolar oxygen gradient, mortality and admission to intensive care unit in severe Covid-19 related pneumonia: a pilot study. Biomed J Sci Tech Res 2020;31(1). DOI: 10.26717/BJSTR.2020.31.005039.

10. Alhazzani W, Møller MH, Arabi YM, Loeb M, Gong MN, Fan E, et al. Surviving sepsis campaign: guidelines on the management of critically ill adults with coronavirus disease 2019 (COVID-19). Crit Care Med 2020;48(6):101. DOI :10.1007/s00134-020-06022-5.

11. Tobin MJ. Basing respiratory management of COVID-19 on physiological principles. Am J Respir Crit Care Med 2020;201(11): 1319-1320. DOI: 10.1164/rccm.202004-1076ED.

12. Mahendra M, Nuchin A, Kumar R, Shreedhar S, Mahesh PA. Predictors of mortality in patients with severe COVID-19 pneumonia - a retrospective study. Adv Respir Med 2021;89(2):135-144. DOI: 10.5603/ ARM.a2021.0036.

13. Ruan Q, Yang K, Wang W, Jiang L, Song J. Clinical predictors of mortality due to COVID-19 based on an analysis of data of 150 patients from Wuhan, China. Intensive Care Med 2020;46(5):846-848. DOI: 10.1007/s00134-020-05991-x.

14. Gupta B, Jain G, Chandrakar S, Gupta N, Agarwal A. Arterial Blood Gas as a Predictor of Mortality in COVID Pneumonia Patients initiated on Noninvasive Mechanical Ventilation: A Retrospective Analysis. Indian J Crit Care Med 2021;25(8):868-873. 